\title{
ASSOCIATION BETWEEN DEPRESSION AND ANXIETY AMONG THE COPD PATIENTS IN A NEPALESE COMMUNITY HOSPITAL: A CROSS SECTIONAL STUDY
}

\author{
Shakya $R^{1^{*}}$, Gautam $B^{2}$
}

\section{Affiliation}

1. Lecturer/ Consultant, Department of Physiotherapy, Kathmandu University School of Medical Sciences, Nepal

2. BPT, Department of Physiotherapy, Kathmandu University School of Medical Sciences, Nepal

\section{ARTICLE INFO}

Received : 02 July, 2019

Accepted : 17 December, 2019

Published : 31 December, 2019

(C) Authors retain copyright and grant the journal right of first publication with the work simultaneously licensed under Creative Commons Attribution License CC - BY 4.0 that allows others to share the work with an acknowledgment of the work's authorship and initial publication in this journal.

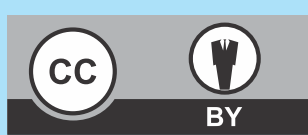

ORA 136

DOI: http://dx.doi.org/10.3126/bjhs.v4i3.27023

\section{* Corresponding Author}

Mr. Regan Shakya

Lecturer/Consultant

Department of Physiotherapy

Kathmandu University School of Medical Sciences, Nepal

Email: reaganshakya@gmail.com

ORCID ID: https//orcid.org/0000-0001-7345-5362

\section{Citation}

Shakya R, Gautam B. Association Between Depression and Anxiety among The COPD Patients In A Nepalese Community Hospital: A Cross Sectional Study. BJHS 2019;4 (3)10:809-812.

\section{ABSTRACT}

\section{Introduction}

Chronic Obstructive Pulmonary Disease (COPD) is a progressive disabling illness characterized by persistent airflow limitation affecting physical, psychological and social aspect of the individual. Amongst the associated co morbidities, depression and anxiety has been identified as a common modifiable psychiatric comorbidities of COPD which impacts the patient's quality of life.

\section{Objective}

To establish the prevalence of depression and anxiety among the COPD patient and determine the association between them.

\section{Methodology}

The cross sectional study was conducted at Dhulikhel Hospital. We used a convenient sampling method to recruit seventy three COPD participants admitted in the Medicine ward. We interviewed the participants to evaluate anxiety and depression using the Nepali version of Hospital Anxiety and Depression Scale questionnaire. We considered positive result of anxiety and depression when the Hospital Anxiety and Depression score was above eight.

\section{Results}

Depressive and Anxiety symptoms were observed in $30 \%$ and $33 \%$ of the participants respectively. Similarly $20 \%$ of the participants had both the symptoms of depression and anxiety. The association between depression and anxiety was found to be highly significant $(p<0.001)$. In the multivariate model the odds of depression and anxiety was nine percent increase with every one year increase in age after adjusting for gender and duration of illness. (adjusted OR: $1.07 ; \mathrm{Cl} 1.00-1.17$; p-value: 0.03 ). In an unadjusted model depression was significantly associated to every year increase in age (unadjusted $\mathrm{OR}: 1.07 ; \mathrm{Cl}: 1.00-1.13$; $\mathrm{p}$-value: 0.03)

\section{Conclusion}

Depression and anxiety is prevalent among COPD patient at Dhulikhel hospital with one fifth of the patient demonstrating both depression and anxiety symptoms.

\section{KEYWORDS}

Anxiety, depression, pulmonary disease 


\section{INTRODUCTION}

Chronic obstructive pulmonary disease (COPD) is a progressive disabling illness characterized by airway inflammation and persistent air flow limitation which is not completely reversible affecting the physical, psychological and social aspects of the individual. ${ }^{1,2}$ The global prevalence of COPD over 40 years is $10.1 \%$; higher in male with prevalence of $11.8 \%$ and in female with prevalence of $8.5 \% .^{3}$ In Nepal, COPD accounts for $33 \%$ of non communicable disease among the age group of $51-80$ years which is comparatively higher than global prevalence among adults over 40 years. ${ }^{4}$ COPD is generally associated with co morbidities. The frequency of hospitalization and premature death in COPD increases with three or more co morbidities. ${ }^{5}$ Comorbidities such as anxiety and depression has a significant effect on the patient, family and society. ${ }^{6,7}$ The effect is observed in medical cost, physical functioning, adherence to treatment, and increased risk of hospitalization. ${ }^{8}$ The prevalence of depression and anxiety of Nepalese population is $11.7 \%$ and $22.7 \%$ respectively. ${ }^{9}$ Psychiatric symptoms such as mood disorders, depression, dysthymias and anxiety are common in COPD and can present at any time during the course of the disease. ${ }^{10}$ However, the perception on the mental health seems to lack among the individuals in Nepal and moreover towards patients with COPD. The lack of identification of mental health among the patients with somatic symptoms brings the patient into a vicious cycle. ${ }^{9}$ The existing state of depression and anxiety affects the ability of the patient to cope with the disease and in process affects the physical symptoms which in turn enforces the depression and anxiety. The major risk factor affecting anxiety is perception of breathlessness and difficulty associated with it. ${ }^{11}$

In COPD patients, reduced recreational activities and social isolation is a major risk factor leading to depression. Cultural differences and diverse communities significantly affect the experience of psychiatric illness in an individual which may discourage them from seeking medical treatment. ${ }^{12}$ Limited studies has been conducted across Nepal associating psychiatric comorbidities in COPD patients. ${ }^{13}$ However, Nepal being a culturally diverse country, the impact of mental illness in health may vary in different communities. Therefore we aim to establish the prevalence of depression and anxiety among the COPD patients in a community hospital and determine the association between them.

\section{METHODOLOGY}

This cross sectional study was conducted between November 2016 and May 2017 at Dhulikhel hospital, a community hospital in Kavre district of Nepal. Dhulikhel Hospital is located at Dhulikhel around $30 \mathrm{~km}$ south east of Kathmandu. We used convenient sampling method to recruit seventy three $(n=73)$ COPD participants. All the participants were admitted at the medicine ward of the Dhulikhel hospital. As selection criteria, we included participants if they had history of COPD for more than one year and aged above 50 years. We excluded the participants who (a) didn't understand Nepali language, (b) didn't communicate verbally, (c) have a hearing impairment, (d) have other chronic disease conditions such as stroke, cancer, and other respiratory conditions.

For the participants' selection, we screened the COPD patients based on the selection criteria. The selected participants were informed about the study procedure, potential risk and benefits. We then obtained a written informed consent document from the participants. At beginning, we collected the basic demographic information such as age (in years), gender (male / female), address, duration of illness (in months). We interviewed the participants in a quiet separate room with the Nepali version of Hospital Anxiety and Depression Scale (HADS) questionnaire. ${ }^{14}$ The baseline characteristics of participants are described in Table 1.

Nepali version of Hospital Anxiety and Depression Scale is valid and reliable tool to measure depression and anxiety among the COPD patients. It is a 14 items questionnaire equally divided into anxiety related items and depression related items. For each item the maximum score is three and minimum score is zero. The scoring for anxiety and depression is done separately on a total score of twenty one each. The score of seven and below is considered normal whereas the score above eleven and above considered abnormal or symptomatic. The score of 8-10 is considered borderline abnormal. ${ }^{15}$

The ethical approval was obtained from International review committee of Kathmandu University School of Medical Sciences/ Dhulikhel Hospital (IRC-KUSMS) with an approval number $91 / 16$.

We summarized the sample characteristics using mean (standard deviation) for continuous variables and frequency (percentage) for categorical variables. We used the descriptive statistics to determine the prevalence of depression, anxiety and both depression and anxiety among COPD patients. We assessed the association between the depression and anxiety of HADS questionnaire using chisquare test. We utilized the multivariate logistic regression model to assess the association between depression and anxiety with age, gender and duration of illness. We used SPSS version 21 for the statistical analysis.

\section{RESULTS}

Table 1 describes the baseline characteristics of the 73 participants. The mean age of the participants was sixty seven years and the mean duration of illness was sixty four years. More than half the participants were male (55\%). Table 2 presents the prevalence of depression, anxiety and both depression and anxiety. It provides the association between depression and anxiety among COPD patients. The prevalence of depression was $30.1 \%$ and the prevalence of anxiety was $32.9 \%$ among the COPD patients. About one fifth of the COPD patients have both depression and anxiety. We found the significant association between depression and anxiety among the COPD patients with the chi-square analysis $(p<0.00)$. 
Table 1: Baseline characteristics of the participants

\begin{tabular}{|l|c|}
\hline Characteristics $(\mathbf{n}=\mathbf{7 3})$ & Mean (SD) / Frequency (\%) \\
\hline Age (years) - mean (SD) & $66.22(9.6)$ \\
\hline Gender Male- $\mathbf{n}(\%)$ & $40(54.8 \%)$ \\
Female- $n$ (\%) & $33(45.2 \%)$ \\
\hline $\begin{array}{l}\text { Duration of illness (months) } \\
\text { - mean (SD) }\end{array}$ & 64.41 (SD 54.4) \\
\hline
\end{tabular}

Table 2: Association between depression and anxiety

within the patients $(n=73)$

\begin{tabular}{|c|c|c|c|c|c|}
\hline \multirow{2}{*}{ Chi-square test } & \multicolumn{2}{|c|}{ Depression } & \multirow{2}{*}{ Total } & P value \\
\cline { 2 - 5 } & Yes & No & \\
Anxiety & Yes & $15(20.5 \%)$ & $9(12.3 \%)$ & $24(32.9 \%)$ & \multirow{2}{*}{$<0.00$} \\
\cline { 2 - 5 } & No & $7(9.6 \%)$ & $42(57.5 \%)$ & $49(67.1 \%)$ & \\
\cline { 2 - 5 } & Total & $22(30.1 \%)$ & $51(69.9 \%)$ & $73(100 \%)$ & \\
\hline
\end{tabular}

Table 3 presents the factors associated with depression and anxiety among the COPD patients. The odd of having both depression and anxiety is $9 \%$ with every one year increase in age after adjusting for gender and duration of illness. In contrast, there was no significant association between age with depression and age with anxiety separately. Similarly, there was no significant association between gender and duration of illness with either depression or anxiety or with both. However in the unadjusted model the odds of depression increase with $7 \%$ with every one year increase in age.

Table 3: Factors associated with depression and anxiety among COPD patients $(n=73)$

\begin{tabular}{|c|c|c|c|c|c|c|}
\hline \multicolumn{7}{|c|}{ Depression } \\
\hline \multirow{2}{*}{ Factors } & \multicolumn{3}{|c|}{ Unadjusted odds ratio } & \multicolumn{3}{|c|}{ Adjusted odds Ratio } \\
\hline & OR & $95 \% \mathrm{Cl}$ & $P$ value & OR & $95 \% \mathrm{Cl}$ & $P$ value \\
\hline Age (years) & 1.07 & $1.0-1.13$ & 0.03 & 1.06 & $0.99-1.13$ & 0.06 \\
\hline $\begin{array}{l}\text { Gender } \\
\text { Male } \\
\text { Female }\end{array}$ & $\begin{array}{c}\text { Ref } \\
0.75\end{array}$ & $0.28-2.07$ & 0.59 & $\begin{array}{l}\text { Ref } \\
1.0\end{array}$ & $0.32-3.12$ & 1 \\
\hline $\begin{array}{l}\text { Duration of } \\
\text { illness }\end{array}$ & 1.0 & $0.99-1.01$ & 0.4 & 1.0 & $0.99-1.01$ & 0.57 \\
\hline \multicolumn{7}{|c|}{ Anxiety } \\
\hline \multirow{2}{*}{ Factors } & \multicolumn{3}{|c|}{ Unadjusted Odds ratio } & \multicolumn{3}{|c|}{ Adjusted Odds Ratio } \\
\hline & OR & $95 \% \mathrm{Cl}$ & P value & OR & $95 \% \mathrm{Cl}$ & $P$ value \\
\hline Age (years) & 1.02 & $0.97-1.07$ & 0.52 & 1.02 & $0.97-1.08$ & 0.48 \\
\hline $\begin{array}{l}\text { Gender } \\
\text { Male } \\
\text { Female }\end{array}$ & $\begin{array}{l}\text { Ref } \\
1.24\end{array}$ & $0.46-3.32$ & 0.67 & $\begin{array}{l}\text { Ref } \\
1.34\end{array}$ & $0.45-3.95$ & 0.6 \\
\hline $\begin{array}{l}\text { Duration of } \\
\text { illness }\end{array}$ & 1.0 & $0.99-1.01$ & 0.53 & 1.0 & $0.99-1.01$ & 0.7 \\
\hline \multicolumn{7}{|c|}{ Depression and Anxiety } \\
\hline \multirow{2}{*}{ Factors } & \multicolumn{3}{|c|}{ Unadjusted Odds ratio } & \multicolumn{3}{|c|}{ Adjusted Odds Ratio } \\
\hline & OR & $95 \% \mathrm{Cl}$ & $P$ value & OR & $95 \% \mathrm{Cl}$ & $P$ value \\
\hline Age (years) & 1.09 & $1.01-1.16$ & 0.02 & 1.09 & $1.00-1.17$ & 0.03 \\
\hline $\begin{array}{l}\text { Gender } \\
\text { Male } \\
\text { Female }\end{array}$ & $\begin{array}{l}\text { Ref } \\
1.51\end{array}$ & $0.48-4.72$ & 0.48 & $\begin{array}{l}\text { Ref } \\
1.0\end{array}$ & $0.27-3.65$ & 1 \\
\hline $\begin{array}{c}\text { Duration of } \\
\text { illness }\end{array}$ & 1.00 & $0.99-1.01$ & 0.59 & 1.0 & $0.99-1.01$ & 0.77 \\
\hline
\end{tabular}

Note: Statistically significant results are presented in bold

\section{DISCUSSION}

This study provides evidence for association between depression and anxiety among the COPD patients. The study also reports that one fifth of population have the symptoms of both depression and anxiety while nearly one third of them have either the symptoms of depression or anxiety. However there was a significant association between depression and anxiety in the COPD patients which suggests that both the symptoms generally coexist together in a disease condition. Similarly the symptoms of depression and anxiety significantly increase with every increase in years irrespective of duration of the disease and the gender of the person. While comparing with anxiety, depression is more likely to increase with age.

In this study, the prevalence of having both depression and anxiety among COPD patients was found to be twenty one percent. This result is lower compared to similar study in rural Nepal which reported a slight higher prevalence of depression and anxiety among COPD patients. ${ }^{13}$ Similarly, an Indian study reported a higher prevalence of $31.3 \%$ of psychiatric state (depression or anxiety) among stable COPD. ${ }^{16}$ Another study in India reported that more than half the population had either depression or anxiety as cormorbidity. ${ }^{17}$ In our study, the prevalence of $30.1 \%$ depression and prevalence of $32.9 \%$ anxiety were within the global prevalence for depression and for anxiety among the COPD patients recovering from acute exacerbation. ${ }^{8}$. Kaneda et al reported a higher prevalence of depression in compared to prevalence for anxiety in COPD patients. ${ }^{18}$ The authors stated that hospitalization and living alone as the major factors for depression and anxiety in those population. Multiple studies in Asia have reported that COPD patient of lower education, solitary living, lower socio-economic status were most likely to be depressed. ${ }^{19}$ However in Nepal, solitary living is uncommon and traditionally, majority of elderly live in joint family taken care by their children relating to the lower prevalence for both anxiety and depression in our findings. ${ }^{20,21}$ Other factors which influences the depression and anxiety are increase in severity of condition and dependency towards oxygen therapy. ${ }^{22,23}$ Eisner et al reported that the COPD patients are likely to have anxiety disorders than the healthy population. ${ }^{24}$

In our study the depressive symptoms and anxiety symptoms were significantly associated with each other. Similarly, we observed a positive association between depression and anxiety with every year increase in age of the patient. However there was no association with other baseline characteristics of gender and duration of illness among the COPD patients. This indicates that age has the major influence over the psychiatric aspect of the patient's condition. Depression and anxiety can occur during any stage of illness but more likely with elderly population. Thapa et al reported a similar finding of no statistical association between depression/anxiety with sociodemographic and clinical characteristics. ${ }^{13}$ In general, depression and anxiety is often reported in women population than the male population due to difference in perception of symptoms. ${ }^{25,26}$ Systematic review have identified efficacy of comprehensive pulmonary rehabilitation (education, exercise, diet modification)in lowering the depression and anxiety in patient with COPD. ${ }^{27} \mathrm{~A}$ similar practice is facilitated clinically at Dhulikhel hospital, with a hour long education session about disease condition, drug 
information and usages, dietary behavior and benefits of exercise followed by circuit exercise training program of one hour. This inpatient rehabilitation is done thrice a week which researches suggests to improve the depressive symptoms and disability in elderly patient with severe COPD. $^{28}$

\section{CONCLUSION}

Depression and Anxiety is common co morbidity among the COPD patients with one fifth of participants having symptoms of both depression and anxiety. Similarly, nearly one third of the participants had either symptoms of depression or anxiety in Nepalese population. There was a significant association between depression and anxiety with every one year increase in age.

\section{RECOMMENDATIONS}

We would recommend for further studies to with larger and diverse population to identify the factors associated with increased risk of developing depression and anxiety among the COPD across Nepal.

\section{LIMITATIONS OF THE STUDY}

There are several limitations in this study. The cross sectional study always measures both risk and condition at one point of time in which we cannot establish the temporality. Many factors which could influence depression and anxiety have not been included in this study. This study was done in one center community hospital in Nepal, so the results might not be generalized.

\section{ACKNOWLEDGEMENT}

We would like to acknowledge the department of internal medicine, Dhulikhel hospital for providing us permits to conduct the study. We would also like to thank Dr. Ajay Risal, MD for providing us permission to use the Nepali version of Hospital Anxiety and Depression questionnaire. We are grateful for the support received from department of physiotherapy during this research.

\section{CONFLICT OF INTEREST}

There are no conflicts associated with this research study.

\section{FINANCIALDISCLOSURE}

This is a self funded research study

\section{REFERENCES}

1. Global initiative for Chronic Obstructive Lung Disease (GOLD): Global strategy for the diagnosis, management, and prevention of chronic obstructive pulmonary disease (2019 report). 2019 [cited 2019 Feb 11]. Available from URL: https://goldcopd.org/gold-reports/

2. Keil DC, Stenzel NM, Kuhl, Vaske I, Mewes R, Kenn K. The impact of chronic obstructive pulmonary disease-related fears on disease-specific disability. Chron Respir Dis. 2014Feb;11(1):31-40. DOI:10.1177/1479972313516881.

3. Negewo NA, McDonald VM, Gibson PG. Comorbidity in chronic obstructive pulmonary disease. Respir Investig. 2015 Nov; 53 (6): 249-58. DOI: 10.1016/j.resinv.2015.02.004

4. Bhandari GP, Angdembe MR, Dhimal M, Neupane S, Bhusal C. State of noncommunicable diseases in Nepal. BMC Public Health. 2014 Jan; 14: 23. DOI: 10.1186/1471-2458-14-23.

5. Barnes PJ, Celli BR. Systematic manifestations and comorbidities of COPD. Eur Respir J. 2009 May; 33(5): 1165-85. DOI: 10.1183/09031936.00128008.

6. Willgoss TG, Yohannes AM. Anxiety disorders in patients with COPD: a systematic review. Respir Care. 2013 May; 58 (5): 858-66. DOI: 10.4187/respcare.01862.

7. Hill K, Geist R, Goldstein RS, Lacasse Y. Anxiety and depression in end-stage COPD. Eur RespirJ.2008Mar;31(3):667-77.DOI: 10.1183/09031936.00125707.

8. Maurer J, Rebbapragada V, Borson S, Goldstein R, Kunik ME, Yohannes AM et al. Anxiety and depression in COPD: current understanding, unanswered questions, and research needs. Chest. 2008 Oct; 134 (4 suppl): 43S-56S. DOI: 10.1378/chest.08-0342

9. Risal A, Manandhar K, Linde M, Steiner TJ, Holen A. Anxiety and depression in Nepal: prevalence, comorbidity and associations. BMC psychiatry. $2016 \mathrm{Apr}$; 16:102. DOI: 10.1186/s12888-016-0810-0

10. Yohannes AM, Alexopoulos GS. Depression and anxiety in patients with COPD. Eur Respir Rev. 2014 Sep; 23 (133): 345-9. DOI: 10.1183/09059180.00007813.

11. Gautam R, Saito T, Kai I. Leisure and religious activity participation and menta health: gender analysis of older adults in Nepal. BMC public Health. 2007 Oct; 7 299. DOI: 10.1186/1471-2458-7-299

12. Falicov CJ. Culture, society and gender in depression. J Fam Ther. 2003 Oct 13;25:371-387. DOI: 10.1111/1467-6427.00256

13. Thapa N, Maharjan M, Shrestha TM, Gauchan S, Pun P, Thapa YB. Anxiety and depression among patients with chronic obstructive pulmonary disease and general population in rural Nepal. BMC psychiatry. 2017 Dec; 17(1): 397. DOI: 10.1186/s12888-017-1550-5.

14. Risal A, Manandhar K, Linde M, Koju R, Steiner TJ, Holen A. Reliability and Validity of a Nepali- language Version of the Hospital Anxiety and Depression Scale (HADS). Kathmandu Univ Med J (KUMJ). 2015 Apr-Jun; 13(50): 115-24. PMID: 26657079

15. Zigmond AS, Snaith RP The hospital anxiety and depression scale. Acta Psychiat Scand. 1983 Jun; 67 (6): 361-70. PMID: 6880820.
16. Dua R, Das A, Kumar A, Kumar S, Mishra M, Sharma K. Association of comorbid anxiety and depression with chronic obstructive pulmonary disease. Lung India. 2018 Jan-Feb; 35 (1): 31-6. DOI: 10.4103/lungindia.Iungindia_537_16

17. Jose A, Chelangara D, Shaji KS. Factors associated with anxiety and depression in chronic obstructive pulmonary disease. Int J Res Sci. 2016 Apr; 4 (4):1074-9. DOI: 10.18203/2320-6012.ijrms20160786

18. Kaneda R, Senjyu H, Iguchi A, Hayashi Y, Iwai S, Tsuda T et al. Factors that Impact Anxiety and Depression in Patients with Chronic Obstructive Pulmonary Disease. J Phys Ther Sci. 2011 Aug: 23 (6): 927-31. DOI: 10.1589/jpts.23.927

19. Lou P, Zhu Y, Chen P, Zhang P, Yu J, Zhang $\mathrm{N}$ et al. Prevalence and correlations with depression, anxiety, and other features in outpatients with chronic obstructive pulmonary disease in China: A cross-sectional case control study. BMC Pulm Med. 2012 Sep; 12: 53. DOI: 10.1186/1471-2466-12-53.

20. Geriatric Center Nepal. Status report on Elderly People $(60+)$ in Nepal on Health, Nutrition and Social status Focusing on Research Needs [online] 2015 [cited 2019 July 7]. Available from: URL: http://ageingnepal.org/status-ofolder-people-nepal/ii

21. Taqui AM, Itrat A, Qidwai W, Qadri Z. Depression in the elderly: Does family system play a role? A cross-sectional study. BMC psychiatry. 2007 Oct; 7:57. DOI: $10.1186 / 1471-244 X-7-57$

22. Van Manen JG, Bindels PJ, Dekker FW, IJzermans CJ, van der Zee JS, Schade E. Risk of depression in patients with chronic obstructive pulmonary disease and its determinants. Thorax 2002 May; 57 (5): 412-6. DOI: 10.1136/thorax.57.5.412

23. Lacasse $Y$, Rousseau L, Maltais F. Prevalence of depressive symptoms and depression in patients with severe oxygen-dependent chronic obstructive pulmonary disease. J Cardiopulm Rehabil. 2001 Mar-Apr; 21(2): 80-6. PMID: 11314288.

24. Eisner MD, Blanc PD, Yelin EH, Katz PP, Sanchez G, Iribarren C et al. Influence of anxiety on health outcomes in COPD. Thorax. 2010 Mar; 65 (3):229-34. DOI: 10.1136/thx.2009.126201.

25. Di Marco F, Verga M, Reggente M, Maria Casanova F, Santus P, Blasi F. Anxiety and depression in COPD patients: The roles of gender and disease severity. Respir Med. 2006 Oct; 100(10): 1767-74. DOI: 10.1016/j.rmed.2006.01.026

26. Laurin C, Lavoie KL, Bacon SL, Dupuis G, Lacoste G, Cartier A et al. Sex differences in the prevalence of psychiatric disorders and psychological distress in patients with COPD. Chest. 2007 Jul; 132 (1): 148-55. DOI: 10.1378/chest.07-0134

27. Coventry PA, Hind D. Comprehensive pulmonary rehabilitation for anxiety and depression in adults with chronic obstructive disease: Systematic review and meta-analysis. J Psychsom Res. 2007 Nov; 63 (5): 551-65. DOI: 10.1016/j.jpsychores.2007.08.002

28. Alexopoulos GS, Sirey JA, Raue PJ, Kanellopoulos D, Clark TE, Novitch RS Outcomes of depressed patients undergoing inpatient pulmonary rehabilitation. Am J Geriatr Psychiatry. 2006 May; 14 (5):466-75. DOI: 10.1097/01.JGP.0000199381.98971.d1 